\title{
Evaluation of analgesic effect of human saliva
}

\begin{abstract}
Opioids are one of the most effective analgesics used commonly in recent times but human saliva is an amazing natural pain killer that produces the analgesic effect as that of opioids. The study is designed to evaluate the analgesic effect of human saliva in different doses. The study is carried out on albino mice weighing $20-25 \mathrm{gm}$. Mice were divided into 5 groups each containing 6 mice. Group I was taken as control and administered distilled water $0.2 \mathrm{ml}$, group II, III and IV were taken as treated. Group II was administered $0.2 \mathrm{ml}$ saliva; group III $0.4 \mathrm{ml}$ and to group IV $0.6 \mathrm{ml}$ saliva was administered. Group V was given acetyl salicylic acid $(300 \mathrm{mg} / 60 \mathrm{~kg})$. The saliva was taken from same healthy female subject for all doses. The tail flick test was performed for evaluation of analgesic effects.

From our study we observed that maximum analgesic effect was observed at 90 minutes (4.6sec \pm 0.10 ) by $0.2 \mathrm{ml}$ dose. However on increasing dose to $0.4 \mathrm{ml}$ maximum analgesic activity was observed at 120 minutes $(6.7 \pm 0.10)$, whereas at $0.6 \mathrm{ml}$ dose maximum effect was observed at 180 minutes (4.6sec \pm 0.08$)$. Maximum activity by standard was observed at 120 minutes $(6.9 \pm 0.09)$

Our study indicates that human saliva at $0.4 \mathrm{ml}$ shows effects like standard however there is significant decrease in analgesic activity as compared to standard (moderate analgesic effect). The results might vary with change in subjects and further studies can be conducted on this point. This study gives us hope that in future it will be very easy to relieve pain especially free of addiction and adverse effects.
\end{abstract}

Keywords: human saliva, analgesic effect, tail flick test
Volume 6 Issue 3 - 2017

\author{
Sana Sarfaraz, Saima Ramzan, Tanveer Bano, \\ Wajeeha Fatima, Ayesha Sabir, Wajiha Riaz \\ Department of Pharmacology, Faculty of Pharmacy, Jinnah \\ University for Women, Pakistan
}

Correspondence: Sana Sarfaraz, Department of Pharmacology Faculty of Pharmacy, Jinnah University for Women, Karachi, Pakistan, Email sana.sarfraz@live.com

Received: October 01, 2017 | Published: October 12, 2017
Abbreviations: APN, amino peptidase N; ANOVA, analysis of variance ; BDNF, brain-derived neurotrophic factor; CGRP, calcitonin gene related peptide; GABA, gamma amino butyric acid; IS, insignificant; NEP, neprilysin ; NSAIDS, non steroidal antiinflammatory drugs; SD, standard deviation

\section{Introduction}

Pain is defined as an unpleasant sensory and emotional experience associated with actual or potential tissue damage. ${ }^{1}$ Pain has two basic types i.e. acute pain and chronic pain, different from each other on the basis of etiology and pathophysiology. Acute pain is independent pain which is consistent with the level of tissue damage. It is a fundamental system for informing and safeguarding injured or damaged regions of body by escaping from noxious stimuli. Whereas chronic or persistent pain is non-independent and treated imperfectly. It is chiefly neuropathic followed by peripheral or central or both type of stimulations. Patients with this type suffer with noteworthy restrictions of activity and physiological instabilities. ${ }^{2-5}$

Analgesics are substances which function to reduce or relief acute and chronic pain by a number of mechanisms in the body. Pain is treated pharmacologically by various agents in which nonsteroidal anti-inflammatory drugs (NSAIDS) for acute and opioids for severe and chronic pain are frequently prescribed. Opioids receptor antagonist such as morphine and its substitutes efficiently alleviate symptoms and treat moderate to severe pain. Mu, kappa and delta are the receptors that produce analgesic effects. ${ }^{5-7}$ Short term relief for various types of pain (including diabetic neuropathy, peripheral neuropathy, post herpetic neuralgia, spinal cord injury with pain below the level of injury, lumbar radiculopathy, phantom limb pain, osteo arthritis, rheumatoid arthritis, low back pain and neck pain) from these agents has also been documented.
Human saliva easily obtainable biological fluid is a natural pain killer which is six times more potent than morphine [8]. Saliva is excreted through oral cavity from sublingual, submandibular and parotid glands. It is sensitive to metabolic variations and its collection can be done through non-invasive and swift procedures..$^{9-11}$ Saliva is a multipart combination of $99 \%$ water but additionally has several electrolytes, small organic molecules (glucose, hormones), proteins (immunoglobulins) and enzymes and glycoproteins. ${ }^{12}$

Opiorphin (peptide I) is a natural inhibitor of enkephalin inactivating enzymes in human neutral ecto-endopeptidase (NEP; neprilysin, ec 3.4.24.11) and human ectoaminopeptidase (apn, ec 3.4.11.2, cd13) that was first detected in human saliva. This peptide exhibits comparable analgesic potency with that of morphine. ${ }^{13}$ Its innovation is extremely exciting from physiological point. Opiorphin is capable to alleviate symptoms of pain efficiently. Besides nociception, opiorphin can alter the progression of adaptation intervened by enkephalins. Thus opiorphin acts by activating endogenous opioid dependent transmission and said to be the modulator of opioid pathways in humans. In accordance with nature, extent and stimuli of pain, opiorphin produces its effect by acting on specific opioid receptor restricted pathway which is stimulated by enkephalins. Enkephalins act on both mu and delta opioid receptors with high affinity and due to their highly essential efficiency they require a small percentage of opioid receptors as compared to morphine to exhibit same analgesic effect. Utilization of smaller proportions of receptors avoids unnecessary stimulation of all over opioid receptors and hence averts various undesirable effects like respiratory depression, constipation sedation and tolerance and dependence that are documented for other opioid antagonist's .Central administration of enkephalins perform a strong and brief analgesic activity attributed to prompt inactivation by the combined action of two membrane-bound metallo-ectopeptidases. They are located near opioid reeceptors named neutral endopeptidase 
(NEP ec3.4.21.11) and aminopeptidase-n (APN ec3.4.11.2). ${ }^{14-15}$ Opiorphin lengthens the effect of enkephalins by obstructing the action of these two enzymes. According to an experimental study in rats $1 \mathrm{mg}$ of opiorphin possesses similar effect of $3 \mathrm{mg}$ of morphine. ${ }^{16}$ The purpose of our study was to evaluate the analgesic effect of saliva at different doses by tail flick test in-order to test the analgesic potential it possesses.

\section{Methodology}

\section{Animals selected}

Albino mice of either sex weighing 20-25grams were selected. The mice were divided into 5 groups, each containing 6 mice. Group I served as control and administered distilled water $0.2 \mathrm{ml}$, group II, III and IV were taken as treated and were given $0.2 \mathrm{ml}, 0.4 \mathrm{ml}$ and $0.6 \mathrm{ml}$ of saliva respectively. Group V was given acetyl salicylic acid $(300 \mathrm{mg} / 60 \mathrm{~kg})$.

Sample collection: The saliva was taken from same healthy female subject for all doses.

Evaluation of analgesic effect: The tail flick test was performed for evaluation of analgesic effects.

\section{Tail flick test}

Respective doses were administered one at a time to all 5 groups and the tail flick test is performed at o minute and then every 30 minutes till 180 minutes. Mice were strained with cuff hold and their tail was dipped in water bath at $50 \mathrm{oC}$ temperature. Tail flick time was noted to observe the analgesic effects. ${ }^{17}$

\section{Statistical analysis}

The experimental results were expressed as Mean \pm SD for six animals in each group. The time taken to flick the tail was analysed statistically using one-way analysis of variance (ANOVA), followed by Tukey's multiple comparison test. P value of $<0.05$ was considered as statistically significant.

\section{Results}

Post hoc analysis by one way ANOVA shows highly significantly increased $(p<0.001)$ tail flick latency time by all three treated doses as compared to control. Upon comparison with standard $0.2 \mathrm{ml}$ of saliva showed highly significantly reduced $(\mathrm{p}<0.001)$ analgesic activity as compared to standard. $0.4 \mathrm{ml}$ dose of saliva also shows highly significantly $(p<0.001)$ reduced analgesic activity till 120 minutes as compared to standard however at 180 minutes it was highly significantly $(\mathrm{p}<0.001)$ increased as compared to standard.

$0.6 \mathrm{ml}$ dose of saliva shows highly significantly $(\mathrm{p}<0.001)$ reduced analgesic effect till 150minutes as compared to standard which was then highly significantly $(\mathrm{p}<0.001)$ increased than the standard at 180 minutes. Among comparison within the group $0.4 \mathrm{ml}$ dose of saliva when compared with $0.2 \mathrm{ml}$ showed highly significant $(\mathrm{p}<0.001)$ increase from 30 till 180 minutes only at 90minutes there was highly significant $(\mathrm{p}<0.001)$ decrease in tail flick latency by $0.4 \mathrm{ml}$ as compared to $0.2 \mathrm{ml}$.

Among comparison within the group $0.6 \mathrm{ml}$ dose of saliva when compared with $0.2 \mathrm{ml}$ showed highly significant $(\mathrm{p}<0.001)$ increase at $30,60,150$ and 180 minutes where as at 90 and 120 minutes there was highly significant $(\mathrm{p}<0.001)$ decrease in tail flick latency by $0.6 \mathrm{ml}$ as compared to $0.2 \mathrm{ml}$. Among comparison within the group $0.6 \mathrm{ml}$ dose of saliva when compared with $0.4 \mathrm{ml}$ showed highly significant $(p<0.001)$ decrease from 60 till 150 minutes where as at 180 minutes there was highly significant $(\mathrm{p}<0.001)$ increase in tail flick latency by $0.6 \mathrm{ml}$ as compared to $0.4 \mathrm{ml}$ (Table 1 ).

Table I Screening of Analgesic activity by Tail Flick Method of human saliva at different doses

\begin{tabular}{|c|c|c|c|c|c|c|c|c|}
\hline Drugs & Dose & Pre Drug (0min) & $30 \mathrm{~min}$ & $60 \mathrm{~min}$ & $90 \mathrm{~min}$ & $120 \mathrm{~min}$ & $150 \mathrm{~min}$ & $180 \mathrm{~min}$ \\
\hline Control & 0. Iml Distill water & $0.60 \pm 0.08$ & $0.68 \pm 0.11$ & $0.70 \pm 0.09$ & $0.70 \pm 0.16$ & $0.73 \pm 0.10$ & $0.70 \pm 0.89$ & $0.68 \pm 0.18$ \\
\hline \multirow[t]{2}{*}{ Saliva } & \multirow[t]{2}{*}{$0.2 \mathrm{ml}$} & \multirow[t]{2}{*}{$0.68 \pm 0.07$} & $\begin{array}{l}1.6 \pm 0.12 \\
* * * *\end{array}$ & $\begin{array}{l}1.8 \pm 0.08 \\
* * *\end{array}$ & $\begin{array}{l}4.6 \pm 0.10 \\
* * * *\end{array}$ & $\begin{array}{l}3.7 \pm 0.12 \\
* * * *\end{array}$ & $\begin{array}{l}3.1 \pm 0.14 \\
* * *\end{array}$ & $\begin{array}{l}2.8 \pm 0.05 \\
* * *\end{array}$ \\
\hline & & & \#\# $\downarrow$ & \#\# $\downarrow$ & \#\#\# $\downarrow$ & \#\# $\downarrow$ & \#\# $\downarrow$ & I.S \\
\hline \multirow{2}{*}{ Saliva } & \multirow{3}{*}{$0.4 \mathrm{ml}$} & \multirow{2}{*}{$0.6 I \pm 0.07$} & $\begin{array}{l}2.3 \pm 0.08 \\
* * *\end{array}$ & $\begin{array}{l}2.7 \pm 0.06 \\
* * *\end{array}$ & $\begin{array}{l}3.2 \pm 0.11 \\
* * *\end{array}$ & $\begin{array}{l}6.7 \pm 0.10 \\
* * *\end{array}$ & $\begin{array}{l}4.2 \pm 0.15 \\
* * *\end{array}$ & $\begin{array}{l}3.8 \pm 0.11 \\
* * *\end{array}$ \\
\hline & & & $\begin{array}{l}\text { \#\# } \downarrow \\
! ! ! \uparrow\end{array}$ & $\begin{array}{l}\text { \#\# } \downarrow \\
! ! ! \uparrow\end{array}$ & $\begin{array}{l}\text { \#\# } \downarrow \\
! ! ! \downarrow\end{array}$ & $\begin{array}{l}\# \downarrow \\
! ! ! \uparrow\end{array}$ & $! ! ! \uparrow$ & $\begin{array}{l}\text { \#\# } \uparrow \\
! ! ! \uparrow\end{array}$ \\
\hline & & & $\begin{array}{l}2.2 \pm 0.18 \\
* * * *\end{array}$ & $\begin{array}{l}2.4 \pm 0.14 \\
* * * *\end{array}$ & $\begin{array}{l}2.3 \pm 0.13 \\
* * * *\end{array}$ & $2.7 \pm 0.12$ & $\begin{array}{l}3.6 \pm 0.10 \\
* * * *\end{array}$ & $\begin{array}{l}4.6 \pm 0.08 \\
* * *\end{array}$ \\
\hline Saliva & $0.6 \mathrm{ml}$ & $0.7 I \pm 0.10$ & $\begin{array}{l}\# \# \downarrow \\
! ! ! \uparrow \\
\text { I.S }\end{array}$ & $\begin{array}{l}\# \# \downarrow \downarrow \\
! ! ! \uparrow \\
\$ \$ \$ \downarrow\end{array}$ & $\begin{array}{l}\# \# \downarrow \downarrow \\
! ! ! \\
\$ \$ \$ \downarrow\end{array}$ & $\begin{array}{l}* * * \\
\# \# \# \downarrow \\
! ! ! \downarrow\end{array}$ & $\begin{array}{l}\# \# \downarrow \downarrow \\
! ! \uparrow \\
\$ \$ \$ \downarrow\end{array}$ & $\begin{array}{l}\# \# \text { \# } \\
! ! ! \uparrow \\
\$ \$ \$ \uparrow\end{array}$ \\
\hline Aspirin & $300 \mathrm{mg} / 60 \mathrm{~kg}$ & $0.9 \pm 0.12$ & $5.2 \pm 0.22$ & $5.3 \pm 0.08$ & $6.4 \pm 0.11$ & $6.9 \pm 0.09$ & $4.1 \pm 0.13$ & $2.8 \pm 0.14$ \\
\hline
\end{tabular}

Values are Mean \pm S.D using Statistical tool SPSS 20 Two way Anova was applied, post hoc Tukeys test shows $P$ values as

$* * * \mathrm{p} \leq 0.00 \mathrm{I}$ : Highly significant compared to control.

$\# p \leq 0.05$ : significant, \#\# $\leq 0.00$ I highly significant compared to standard.

!!!p $\leq 0.00 \mathrm{I}$ : Highly significant when compared among treated groups $(0.4 \& 0.6 \mathrm{ml}$ against $0.2 \mathrm{ml})$.

$\$ \$ \$ p \leq 0.00$ I: Highly significant IS insignificant when compared among treated groups $(0.6 \mathrm{ml}$ against $0.4 \mathrm{ml})$.

\section{Discussion}

Pain is defined as an unpleasant sensory and emotional experience associated with actual or potential tissue damage. Analgesia is alleviation or absence of pain. Prostaglandins are pro-inflammatory chemicals which are normally produced by body as a consequence of tissue damage and have significant role in process of pain and inflammation. Analgesic effect can thus be produced by reducing the production of prostaglandins that act as pro-inflammatory mediators. ${ }^{18}$ Human saliva contains natural pain killer "opiorphin" 
it acts by activating endogenous opioid dependent transmission and is said to be the modulator of opioid pathways in humans. Opoiorphin is a relatively simple molecule consisting of a five-amino acid polypeptide, Gln-Arg-Phe-Ser-Arg. Opiorphin pentapeptide originates from the N-terminal region of the protein PROL1 (prolinerich, lacrimal 1). ${ }^{19}$ Opoiorphin also possess anti-panic and antidepressive activity. ${ }^{20}$

The aim of the present study was to investigate the pharmacological functional profile of opiorphin as an analgesic with respect to doses and efficacy of analgesic effect. Our aim was to access the potency and the duration of opiorphins analgesic effect here we use tail flick method for analyzing the analgesic effect and hence we observed that the analgesic effect of saliva (opiorphin) depends upon quantity of dose and subject from which saliva has been taken. Tail flick test is a model of central pain evaluation. This test constitutes a well validated model for detection of opiate like analgesic drugs where pain response is from spinal origin. ${ }^{21}$ This method was used because it is simple and inexpensive. This method involves thermal nociceptors stimulation. Specific nociceptors involved in thermal pain perception are thermo sensitive non selective cationic channel specifically Transient receptor potential vanilloid receptor 1 (TRPV1) and Transient receptor potential vanilloid receptor protein 1 (TRPV2). ${ }^{22}$ TRPV 1 are expressed in high threshold peripheral neurons and activated at temperature excess of $42^{\circ} \mathrm{C}$. While TRPV2 receptors are activated at temperature above $50^{\circ} \mathrm{C}$. It has been reported in literature by that opioidal drugs have both central and peripheral pain blocking mechanism. ${ }^{23}$ It is well established that thermal nociceptive test are more sensitive to $\mu$ opioidal agonist or central analgesics, so our study represent that here $\mu$ opioidal receptors are activated and producing analgesic effect .The neurotransmitter involved in pain mainly is glutamate while co transmitters involved are substance P, CGRP (Calcitonin gene related peptide), BDNF (Brain-derived neurotrophic factor) etc. Other neurotransmitters Norepinephrine, serotonin, dopamine, glycine, GABA (gamma amino butyric acid), opioidal peptides released from inhibitory neurons are involved in pain inhibition. ${ }^{24}$

Our study indicates that human saliva at $0.4 \mathrm{ml}$ shows effects like standard (aspirin). However there is significance decrease in analgesic activity as compared to standard (moderate analgesic effect). Literature studies of opiorphin have been characterized in human as inhibition of both zinc ecto-peptidases nep and ap-n, that participate in the inactivation of the endogenous opioid neuropeptides enkephalins. ${ }^{25}$ It is also stated that in most of murine models of pain, opiorphin has been shown to produce an analgesic effect as compared to morphine by activation of the endogenous opioid pathways, without causing a drug tolerance, dependence or constipation. ${ }^{26}$ Thus, all these findings lead us to conclude that opiorphin which is an inhibitor of pain sensation works by inhibiting the breakdown of the endogenous enkephalin-related activation of $\mu$-and $\delta$-opioid pathways.

\section{Conclusion}

The aim of the present study was to investigate the analgesic effect of saliva at different doses. We used tail flick method for analyzing the analgesic effect. Our study indicates that human saliva at $0.4 \mathrm{ml}$ shows somewhat similar effects like standard (acetyl salicylic acid).Hence we concluded that saliva posseses analgesic effect which might be due to opiorphin which is natural pain killer found in saliva having less side effects. This study gives us hope that in future it will be very easy to relieve pain especially free of addiction and adverse effects. Further researches and experimental studies can be carried out by isolating opiorphin molecule from saliva as it is a simple molecule and its analgesic effects should be compared with morphine.

\section{Acknowledgements}

None.

\section{Conflicts of interest}

None.

\section{References}

1. Williams AC, Craig KD. Updating the definition of pain. Pain. 2016;157(11):2420-2423.

2. Merskey H, Bogduk N. Pain terms, a current list with definitions and notes on usage. Classification of Chronic Pain Seattle, International Association for the Study of Pain (IASP) Press, USA, 1994. p. 209-214.

3. McQuay H. Opioids in pain management. Lancet. 1999;353(9171):2229-2232.

4. Meert TF, Vermeirsch HA. A preclinical comparison between different opioids: antinociceptive versus adverse effects. Pharmacol Biochem Behav. 2005;80(2):309-326.

5. Daniel GJ, Andrew M, Micheal K, et al. The Pain Interactome: Connecting Pain-Specific Protein Interactions. Pain. 2015;155(11):2243-2252.

6. Tenovuo JO. Salivary parameters of relevance for assessing caries activity in individuals and populations. Comm Dent Oral Epidemiol. 1997;25(1):82-86

7. M Usman Tahir, Najma Shoaib, Arooj Usman, et al. Prevalence of Analgesic Use amongst University Students. PJMHS. 2011;5(4):775-777.

8. https://www.news-medical.net/news/2006/11/15/21008.aspx

9. Andy Coghlan. Natural-born Pain Killer Found in Human Saliva. Journal Ref Proceedings of the National Academy Of Science. 2016;1(3):17979.

10. Joao F, Sandra GF, Ohman C, et al. Metabolite Quantification By NMR and LC-MS/MS Reveals Differences Between Unstimulated, Stimulated and Pure Parotid Saliva. J Pharm Biomed Anal. 2017;140:395-400.

11. Zhang YF, Zheng J, Zhou ZR. Influence of Centrifugation Treatment on the Lubricating Properties of Human Whole Saliva. Biosurface and Biotribology. 2016;2(3):96-101.

12. Gittings S, Turnbull N, Henry B, et al. Characterisation of Human Saliva as a Platform for Oral Dissolution Medium Development. European Journal of Pharmaceutics and Biopharmaceutics. 2015;91:16-24.

13. Anne Wisner, Evelyne Dufour, Michaël Messaoudi, et al. Human Opiorphin, a natural antinociceptive modulator of opioid-dependent pathways. Proc Natl Acad Sci USA. 2016;103(47):17979-17984.

14. Rougeot C, Robert F, Menz L, et al. Systemically Active Human Opiorphin Is a Potent yet Non-Addictive Analgesic without Drug Tolerance Effects. J Physiol Pharmacol. 2010;61(4):483-490.

15. Carpenter GH. The secretion, components, and properties of saliva. Annu Rev Food Sci Technol. 2014;4:267-276.

16. Brand HS, Veerman CI. Saliva and Wound Healing. Chin J Dent Res. 2013;16(1):7-12.

17. Gorzalczany S, Marrassini C, Miño J, et al. Antinociceptive Activity of Ethanolic Extract and isolated Compounds of Urticacircularis. Journal of Ethnopharmacology. 2011;134(3):733-738.

18. Pleuvry B. Non-opioid analgesics. Anesthesia and intensive care medicine. 2005;6:25-29.

19. Dickinson DP, Thiesse M. cDNA cloning of an abundant human lacrimal gland mRNA encoding a novel tear protein. Curr Eye Res. 1996;15(4):377-386. 
20. Avelot H, Messaoudi M, Garnier S, et al. Human opiorphin is a naturally occurring antidepressant acting selectively on enkephalin-dependent delta-opioid pathways. J Physiol Pharmacol. 2006;61(3):355-362.

21. Gupta M, Mazumder UK, Sambath R, et al. Antiinflammatory, analgesic and antipyretic properties of methanolic extract of $\mathrm{C}$. bounducella leaves in experimental animal models. Iranian Journal of Pharmacology \& Therapeutics. 2003;2(2):30-34.

22. Pata Poutian A, Tate S, Wolf CJ. Targeting pain at the source. Nat Rev Drug Discovery. 2009;8(1):55-56.

23. Kathryn Bayne. Assessing pain and distress. A veterinary behaviorist perceptive by Kathryn Bayne. Definition of pain and distress and reporting requirement for laboratory animals. 2010.
24. Pranit KP, Pawar Jayashree C, Chaaudri Sanay R. Central nervous system activity of different extracts of Leucas longifolia Benth. Asian Journal of Pharmaceutical and clinical Research. 2010;3(4):48-52.

25. Thanawala V, Kadam VJ, Ghosh R. Enkephalinase inhibitors: potential agents for the management of pain. Curr Drug Targets. 2008;9(10):887-894.

26. Rougeot C, Messaoudi M, Hermitte V, et al. Sialorphin, a natural inhibitor of rat membrane-bound neutral endopeptidase that displays analgesic activity. Proc Natl Acad Sci USA. 2003;100(14):8549-8554. 